\section{A subordinação do jornalismo à lógica capitalista da indústria cultural}

\section{RESUMO}

0 presente trabalho visa refletir sobre a implantação da indústria cultural no Brasil, particularmente no ramo da imprensa, e sobre as implicações da introdução da lógica empresarial no jornalismo. Tais reflexões são desenvolvidas a partir de pesquisa bibliográfica sobre 0 assunto, circunscrita, em linhas gerais, à perspectiva teórica da economia política das comunicações. Para a consecução desses objetivos, iniciaremos fazendo um resgate histórico e do contexto econômico e político de implantação da indústria cultural no Brasil. Num segundo momento, trataremos da perspectiva teórica que orienta nossa leitura do assunto - a economia política -, procurando esclarecer seus pressupostos fundamentais. Por fim, procuraremos tratar com mais especificidade das implicações da introdução da lógica da indústria cultural no jornalismo.

\section{ABSTRACT \\ This article intends to reflect upon the start of the cultural industry in Brazil, particularly on the press, and on the implications of the introduction of the logic of business in journalism. Such reflections are developed from text researches carried on the subject, circumscribed to a theoretical perspective about economic policies of com- munication.}

PALAVRAS-CHAVE (KEY WORDS)

- Técnica (Technics)

- Devir (Becoming)

- Nietzsche
A implantação da indústria cultural no Brasil

O processo de implantação de um mercado de bens simbólicos no Brasil tem início nos anos 60 e consolida-se na década de 70. Começa ainda no período do governo desenvolvimentista de Juscelino Kubitschek (1956-1960) e se aprofunda nos governos militares pós-1964. A esse mercado que se constitui como um sistema de complexos empresariais ligados ao ramo da cultura e da comunicação de massa é que se convencionou chamar "indústria cultural". A expressão foi cunhada por Adorno e Horkheimer, dois dos mais conhecidos filósofos da Escola de Frankfurt, para designar o conjunto de organizações empresariais, altamente concentradas tecnicamente e de capital centralizado, que produzem e distribuem objetos culturais em grande escala, empregando métodos muitas vezes (embora nem sempre) marcados por um alto grau de divisão do trabalho, baseados em fórmulas, e visando à rentabilidade econômica.

Autores como Lopes (1994), Ortiz (1991) e Taschner (1992) discorrem com maior propriedade sobre o assunto que aqui abordaremos apenas sinteticamente, de maneira a contextualizar o fenômeno sobre o qual pretendemos discorrer mais detidamente, que é as implicações da lógica empresarial sobre o jornalismo. Os autores em referência compartilham dados históricos que permitem sustentar as informações quanto ao surgimento e a consolidação da indústria cultural nos anos 60 e 70, respectivamente. Cada um deles, entretanto, dá maior realce, maior ênfase, a um ou outro aspecto do processo, conforme 
os seus interesses de pesquisa.

Lopes (1994) sustenta que a etapa de constituição de um mercado cultural no Brasil teve início no governo Juscelino Kubitschek e se desenvolveu com base na ideologia desenvolvimentista que marca esse período. Taschner (1992), na mesma direção, lembra que foi a partir de meados dos anos 60 que começam a se evidenciar, a ganhar proeminência no cenário nacional, organizações como Globo e Abril, seguidas depois por Folhas, O Estado de São Paulo e Manchete. Observa, entretanto, que embora fosse se gestando aos poucos, algumas características e formas de organização da indústria cultural podem ser identificadas há mais tempo, como veremos adiante, no item três. Ortiz (1991), por sua vez, acrescenta que a tv se concretiza como veículo nos anos 60 e que o cinema se estrutura como indústria nos anos 70 .

Os autores estão de acordo tanto quanto ao período em que ocorre a consolidação do fenômeno no Brasil quanto ao papel exercido pelos governos pós-1964 nesse processo. Taschner (1992) diz que, apesar de as condições para o desenvolvimento de uma indústria cultural virem se criando ao longo do tempo, dois fatos em particular facilitam muito o seu desenvolvimento a partir dos anos 60 e completam a formação de suas bases materiais: a) o ingresso do Brasil na etapa monopolista do capitalismo e b) o reordenamento político do país após o golpe de 64.

Quanto ao ingresso do país na etapa monopolista do capitalismo, a autora argumenta que, em virtude do seu caráter tardio, ao término do processo de industrialização, este se fez apoiado não só no capital privado nacional, como também no capital estrangeiro e no capital estatal, que teve grande peso e atuação. "Completar a industrialização não significa que os problemas prévios de 'subdesenvolvimento' ou heterogeneidade interna (...) tenham sido adequadamente equacionados, ao contrário. Mas significa que o processo de acumulação entrou em uma nova etapa, cuja dinâmica passou a assentar em um padrão 'especificamente capitalista'." (Taschner, 1992:103).

No que diz respeito ao reordenamento político a partir do golpe de 64, a autora observa ter se formado um pacto de poder - baseado em uma aliança entre a burguesia, as classes médias e os militares - que excluía rigorosamente as classes populares. Essa aliança, entretanto, segunda a socióloga, não incluía todos os setores da burguesia e das classes médias. Segundo ela, os setores tradicionais das classes médias e os ligados à grande propriedade rural, que inicialmente faziam parte da aliança, foram progressivamente alijados das posições de poder dentro do Estado em benefício dos 'grupos modernos' (o setor da burguesia empresarial que se organizou na grande empresa e os setores de classe média que se escudam no Estado empresarial e na grande empresa, inclusive e principalmente os militares).

Assim, conclui, "foi nos marcos do capitalismo monopolista tardio e sob a égide de um regime político burocráticoautoritário de controle militar, no qual boa parte dos direitos de cidadania foi restringida ou inexistente, que a indústria cultural viveu um período de grande desenvolvimento, o qual, em função de tal enquadramento, ganharia certa especificidade." (Taschner, 1992:105).

Segundo essa análise, alguns aspectos favoráveis à indústria cultural derivam do próprio monopolismo; outros, de medidas econômicas do governo, no sentido de gerir a crise e preparar as bases do novo ciclo de expansão; ou ainda do próprio autoritarismo do regime; ou, finalmente, do cruzamento desses fatores.

A conjuntura político-econômica do período de implantação da indústria cultural no Brasil também é descrita por Lopes (1994). Para a autora, a etapa de implantação teve início com o governo JK e se desenvolveu com base na ideologia desenvolvimentista implementada. A 
política de aprofundamento do processo de substituição de importações fez com que, em poucos anos, o país passasse da produção de bens de consumo nãoduráveis para a produção de bens duráveis de consumo, de insumos industriais e de bens de equipamento. Esse desenvolvimento se fez, segundo a autora, com a massiva participação de capitais estrangeiros, que passaram a dominar os ramos-chave do aparelho industrial. Com isso, na sua avaliação, estaria configurado o modelo "associado" de desenvolvimento em contraposição ao modelo "nacionaldesenvolvimentista" do período anterior.

O modelo aprofunda-se ao longo dos governos militares (1964-1985) e torna-se parte das rearticulações globais do capital internacional que repõe, em outras bases, não apenas as questões econômicas, mas também políticas e culturais, da dependência e da autonomia dos países periféricos. Assim, ratificando os principais fatores apontados por Taschner (1992) no processo de implantação e desenvolvimento de uma indústria de bens culturais no Brasil a partir dos anos 60, Lopes acrescenta: “(...) a história recente da sociedade brasileira mostra que o governo militar combinou dois aspectos não necessariamente antagônicos: a organização de um Estado autoritário e o desenvolvimento econômico." (Lopes, 1994:23).

O golpe militar de 1964 é um ponto de inflexão igualmente importante para Ortiz (1991), que, ao analisar a evolução da indústria cultural no Brasil, diz que o fenômeno precisa ser vinculado a razões de fundo, às transformações estruturais que se processam na sociedade brasileira nesse momento.

O antropólogo paulista também é um dos que observa que o estado militar inaugurado em 1964 tinha um duplo significado. Era, concomitantemente, um projeto político e um projeto econômico. Do ponto de vista da sua dimensão política, estava inspirado na Ideologia de
Segurança Nacional (ISN), o fundamento do pensamento militar em relação à sociedade. Essa ideologia concebe o Estado como uma entidade política que detém o monopólio da coerção, a faculdade de impor - inclusive pela força - as normas de conduta a serem obedecidas por todos. Trata-se de um Estado percebido como o centro nevrálgico de todas as atividades sociais relevantes em termos políticos. Vem daí, segundo ele, a preocupação constante com a integração nacional. "Uma vez que a sociedade é formada por partes diferenciadas, é necessário pensar uma instância que integre, a partir de um centro, a diversidade social." (Ortiz, 1991: 115) Por esse tipo de raciocínio, tudo o que contribua para a disfunção desse sistema deve ser reprimido, punido, banido.

Daí a censura, os exílios, as prisões. O autor diz ainda que a ISN se propunha a substituir o papel que as religiões desempenhavam nas sociedades tradicionais, quando o universo religioso soldava organicamente os diferentes níveis sociais, gerando solidariedade entre as partes e assegurando a realização de determinados objetivos.

"Procura-se garantir a integridade da nação com base em um discurso repressivo que elimina as disfunções, as práticas dissidentes, organizandoas em torno de objetivos pressupostos como comuns e desejados por todos". (Ortiz, 1991:115)

A dimensão econômica do regime militar define-se pelo projeto de desenvolver a economia brasileira e inserila no mercado internacional. Para isso, são tomadas medidas que aprofundam mudanças iniciadas ainda no período JK e que reorganizam a economia como um todo. Na mesma linha de argumento de Taschner (1992), Ortiz (1991) diz que o Estado autoritário permite consolidar no Brasil o chamado "capitalismo tardio".

Em termos culturais, essa 
reorganização econômica produz conseqüências imediatas: paralelamente ao crescimento do parque industrial e do mercado interno de bens materiais, fortalece-se o parque industrial de produção de cultura e o mercado de bens culturais. A expansão dessas atividades culturais, entretanto, faz-se associada a um controle estrito das manifestações que se contrapõem ao pensamento autoritário. Aqui, Ortiz (1991) chama atenção para a diferença existente entre o desenvolvimento de um mercado de bens materiais e um mercado de bens culturais.

Segundo o antropólogo, o mercado de bens culturais envolve uma dimensão simbólica que aponta para questões ideológicas, expressam uma aspiração, um elemento político embutido no próprio produto. Por isso, essa área tem um tratamento diferenciado do Estado. "A cultura pode expressar valores e disposições contrárias à vontade política dos que estão no poder." (Ortiz, 1991: 114) É preciso vigiar, incentivar o desenvolvimento da indústria cultural, já que ela é fundamental para o projeto de poder, mas manter-se quanto aos excessos. Para desempenhar esse trabalho de vigilância permanente é que existe a censura.

$O$ autor em referência alerta para a necessidade de se observar as duas faces da censura existente no período. Uma de suas faces, segundo ele, é repressiva; a outra, disciplinadora. A face repressiva é a puramente negativa, a que diz não, que veta, proíbe. A disciplinadora é mais complexa, afirma e incentiva um determinado tipo de orientação. Ortiz (1991) assegura que, de 1964 a 1980, a censura não se define exclusivamente pelo veto a todo e qualquer produto cultural. Diz que ela age como repressão seletiva que impossibilita a emergência de um determinado pensamento ou obra artística. "São censurados as peças teatrais, os filmes, os livros; mas não o teatro, o cinema ou a indústria editorial." (Ortiz, 1991: 114)
Com isso, quer dizer que 0 ato censor atinge a especificidade da obra, não a generalidade da sua produção.

Por essa razão, o Estado de Segurança Nacional não só detém o poder da censura, como também se interessa pelo desenvolvimento de certas atividades culturais, desde que submetidas às razões de Estado. Reconhece, portanto, que a cultura envolve uma relação de poder, que pode ser "perigosa" quando nas mãos de dissidentes do regime, mas benéfica quando circunscrita ao poder autoritário. É por perceber a importância de atuar junto às esferas culturais que, segundo o autor, o Estado vai promover a criação de instituições como a Embrafilme, a Funarte, o Pró-Memória, etc. Pela mesma razão, argumenta, vai reconhecer a importância dos meios de comunicação de massa, pela sua capacidade de difundir idéias, de se comunicar diretamente com as massas e, sobretudo, pela possibilidade de criar estados emocionais coletivos, o que era essencial para a consecução dos objetivos de integração nacional.

A idéia de integração nacional, aliás, é um ponto de convergência de interesses entre os militares no poder e a classe empresarial portadora de um capitalismo que, aos poucos, segundo Ortiz, vai se desprendendo da sua insipiência. Ocorre que "integração nacional" tinha um sentido para os militares e outro sentido para a classe empresarial.

Para os militares, integrar significava a união nacional - de norte a sul, de leste a oeste - em torno de objetivos comuns representados pelo projeto da ISN, criando assim, fortemente, uma idéia de nação, coesa, com a qual todos os brasileiros, indiferenciadamente, estariam empenhados e comprometidos. Significava a unificação das consciências. Para os empresários, integração nacional significava tão-somente integração de mercados.

Os diferentes sentidos, entretanto, não significavam empecilho para a convergência de interesses entre uns e outros. Para 
levar adiante o projeto de integração nacional, o Estado militar implantou toda uma infra-estrutura de comunicações cujos benefícios serão colhidos pela classe empresarial, interessada na integração dos mercados consumidores. É a partir dessa convergência de interesses que, segundo Ortiz (1991) se dá a colaboração efetiva do regime militar para a expansão dos grupos privados. E o melhor exemplo dessa colaboração, na sua percepção, é o desenvolvimento da televisão, que - até os anos 50 - padecia de enormes dificuldades técnicas. Conforme o autor, com a criação da Embratel e do sistema internacional de satélites, em 1965, do Ministério das Comunicações, em 1967, e com a inauguração do sistema de microondas, em 1968 (completado em 1970, com a inclusão da Amazônia), permitindo a interligação de todo o território nacional, ficavam superadas as dificuldades técnicas que impediam a implantação de um sistema de redes. Esse sistema, essencial para a indústria cultural, especialmente para a televisão, pressupôs um suporte tecnológico financiado pelo Estado, ao contrário do que ocorreu nos Estados Unidos, onde resultou de investimentos privados.

Dessa forma, o que justifica a ação dos militares na implantação de uma infraestrutura que permite o desenvolvimento das telecomunicações é a ISN e a idéia central de integração. Como, entretanto, - Estado atua e privilegia sua intervenção direta é na área econômica, quem colhe os frutos desse investimento estatal são empresários da televisão, particularmente a Rede Globo.

A relação entre empresários e militares, contudo, não se deu sem conflitos. Ortiz (1991) lembra que os interesses dos empresários da cultura e do Estado eram os mesmos, embora topicamente pudessem diferir. Nesses termos, a própria censura pode ser melhor compreendida, segundo ele. $\mathrm{O}$ autor observa que a ISN era moralista (no sentido político, de costumes) e a dos empresários, mercadológica. Em razão disso, o conflito se instaura quando a censura torna-se excessivamente rigorosa na sua incidência sobre o produto (jornais, canções, filmes, etc.) e com isso prejudica a sobrevivência econômica das empresas. Um jornal que tenha, pela ação da censura, comprometida a sua credibilidade, seu principal capital, perderá leitores e conseqüentemente anunciantes. Como equacionar essa questão, uma vez que os empresários da cultura e das comunicações são benefiários do Estado? Segundo o autor de A moderna Tradição Brasileira, um dos mais completos relatos sobre a indústria cultural no Brasil, a saída encontrada foi uma ação seletiva da censura: a crítica se desloca do campo político para o campo econômico. Ao mesmo tempo em que é um incômodo para o crescimento da indústria cultural, a censura é o preço a ser pago pelo fato de serem os militares os incentivadores do desenvolvimento brasileiro, avalia o antropólogo.

Assim, a partir dos anos 70, a indústria cultural no Brasil passa por uma formidável expansão, tanto no que diz respeito à produção, quanto à distribuição e ao consumo. Crescem a produção de livros, a publicidade, o mercado editorial, a indústria gráfica, cinematográfica, jornalística, de entretenimento, etc., e consolidam-se conglomerados como a Editora Abril, o grupo Folhas, Organizações Globo, O Estado de São Paulo, etc. Nas décadas seguintes, esse crescimento continua com o surgimento das mais diversas publicações e produtos culturais que vão atender à demanda dos públicos mais amplos e variados.

Dessa forma, como muito bem analisa Ortiz (1991), o movimento cultural pós-64 caracteriza-se por duas vertentes não excludentes. Por um lado, define-se pela repressão ideológica e política; por outro, pelo momento da história brasileira em que mais são produzidos, difundidos e consumidos bens culturais. A indústria cultural chega, assim, à década de 70 
plenamente consolidada.

A economia política como alternativa de reflexão

A indústria cultural tem sido um dos mais produtivos objetos de estudo tanto no campo específico da Comunicação quanto em outros, de disciplinas até mais consolidadas, como Sociologia, Filosofia, Ciência Política, História. Desde que passou a se configurar como um fenômeno relevante na sociedade brasileira, a exemplo do que ocorreu no restante do mundo, particularmente nos Estados Unidos e na Europa, vem sendo analisada tanto nas suas facetas particulares como na sua totalidade fenomênica. Muitas têm sido as perspectivas teóricas e metodológicas adotadas para a sua investigação ao longo do tempo e, superada uma primeira fase de estudos, marcada pelo antagonismo e pelo enfrentamento ideológico (pesquisa administrativa norte-americana $\mathrm{x}$ pesquisa crítica européia), chega-se aos dias atuais compartilhando um relativo consenso quanto à sua natureza complexa, que requer, em conseqüência, a pluralidade de muitos olhares, a partir de muitos lugares, de distintas distâncias e enquadramentos.

Para os objetivos do presente ensaio, para o tipo de problema que nos dispomos a discutir, acredita-se pertinente a perspectiva da economia política das comunicações como alternativa de análise, como base de explicação, por tratar-se de teoria realista, inclusivista e crítica. Realista porque parte do pressuposto de que o mundo é feito de observações sensoriais e interpretações; inclusivista porque consciente de que é apenas mais uma entre tantas possibilidades de explicação de um fenômeno; e crítica, tanto em relação à economia política como um todo como em relação às teorias da comunicação em geral. $^{2}$

Para melhor compreensão do lugar de onde se está a investigar o fenômeno jornalismo de indústria cultural, cabe esclarecer alguns dos pressupostos concernentes a essa perspectiva teórica, inclusive de forma a melhor situá-la entre as tantas teorias de que nos valemos para pesquisar no campo da comunicação.

Conforme Mattellart (1999), a economia política da comunicação começa a se desenvolver como perspectiva analítica ainda na década de 60, assumindo, de início, a forma de um questionamento sobre o desequilíbrio dos fluxos de informação e produtos culturais entre países desenvolvidos e subdesenvolvidos. A partir de 1975, entretanto, encaminhase para uma reflexão não mais sobre a indústria cultural, mas sobre "as indústrias culturais", que passa a ser o lugar central de interesse dos pesquisadores, especialmente os franceses. Isso significa o abandono de um conceito caro à Escola de Frankfurt e conseqüentemente uma ruptura com essa perspectiva teórica. Nesse período, passam a se interrogar acerca dos problemas encontrados pelo capital para produzir valor a partir da arte e da cultura. Refutam a idéia de que a produção da mercadoria cultural (livro, disco, cinema, jornal, tv, etc.) responda a uma só e mesma lógica, argumentando que a indústria cultural em si não existe, mas que é um composto constituído por elementos que se diferenciam fortemente uns dos outros, por setores que apresentam suas próprias leis de padronização. Essa segmentação da indústria cultural pelo capital, explica Mattelart, traduz-se nas modalidades de organização do trabalho, na caracterização de seus próprios produtos e em seu conteúdo, nos modos de institucionalização das diversas indústrias culturais, no grau de concentração (horizontal e vertical) das empresas de produção e de distribuição, ou ainda na maneira pela qual os consumidores ou usuários se apropriam dos seus produtos e serviços.

Mesmo sendo um dos herdeiros do paradigma marxista, os teóricos da economia política rompem também com 
as teses clássicas do marxismo a respeito da história do capitalismo moderno. Essas teses sustentavam o caráter revolucionário do modo de produção capitalista pela capacidade deste em se transformar continuamente. Por essa lógica, a expansão e o progresso permanente, no seio do modo de produção, criariam as condições para a sua própria queda, ao aprofundar as contradições das forças sociais. Mattelart (1999) explica que, a essa visão da história, a economia política vai contrapor-se dizendo que a história do capitalismo moderno em numerosos países não corresponde a esse esquema e que o que se assiste em muitas regiões do mundo é "o desenvolvimento do subdesenvolvimen to".

Com isso, também abandonam a sociedade nacional como unidade de análise e passam a trabalhar com a idéia de sistema-mundo. A partir desse novo modelo de análise, as indústrias culturais, pesquisadas na sua lógica particular, precisam ser vistas no cenário do capitalismo internacional, que se difunde alheio às fronteiras dos Estados-nação. $O$ conceito de economia-mundo passa a ser fundamental na medida em que se define, de acordo com Mattelart (1999), a partir de uma tripla realidade: um espaço geográfico dado; a existência de um pólo (o centro do mundo), onde são tomadas as decisões mais importantes acerca do gerenciamento do capitalismo em escala global; e as zonas intermediárias em torno desse centro, de margem bastante ampla, que, na divisão do trabalho, acham-se subordinadas e dependentes das necessidades do centro.

Esse esquema, segundo o autor, recebe o nome de troca desigual, o que significa que o capitalismo é percebido como a criação da desigualdade no mundo e só pode ser compreendido num espaço universalista. $O$ mapa das redes comerciais de produção e distribuição de comunicação e cultura constitui parte essencial, manifesta, dessa configuração centrípeta do mundo, com suas hierarquias e coexistência de modos de produção diferentes.

É partindo desse modelo de análise que consideramos imprescindível compreender o fenômeno de implantação e desenvolvimento da indústria cultural no Brasil, especialmente quando atentamos para o cenário político e especialmente econômico em que o fenômeno ocorre - de inclusão tardia da economia brasileira no capitalismo internacional.

Também por compartilhar da idéia de que não existe uma mesma lógica para todas as indústrias culturais é que as reflexões que nos propomos no presente trabalho restringem-se ao jornalismo de indústria cultural, particularmente 0 jornalismo impresso, não podendo ser generalizadas, portanto, a indústrias de natureza diferente embora pertencentes ao mesmo ramo da produção de bens para consumo imaterial.

Implicações da lógica de indústria sobre o jornalismo

De acordo com uma das mais importantes pesquisadoras brasileiras do assunto, a socióloga Gisela Taschner, o que caracteriza fundamentalmente uma imprensa de indústria cultural é a subordinação da mensagem jornalística à lógica empresarial. As notícias, as informações, são concebidas integralmente como mercadorias, não apenas porque são produzidas com o emprego de técnicas próprias da indústria cultural, mas também porque estão sujeitas à sua lógica (Taschner, 1987 e 1992).

A autora pesquisa o fenômeno no segmento da imprensa através de um estudo de caso do Grupo Folhas ${ }^{3}$, que edita, entre outros jornais, a Folha de São Paulo. Sua estratégia de trabalho foi, recuperando a história de formação desse conglomerado, reconstituir a evolução das relações que se estabeleceram entre os jornais e as empresas em que são produzidos. O objetivo manifesto 
era investigar quando e como a forma empresarial das organizações e a preocupação com o mercado passaram a ser o elemento mais importante na determinação da lógica de produção das mensagens jornalísticas. Tratou, portanto, de ver o processo pelo qual as empresas, que antes serviam apenas de suporte para a elaboração do jornal, passaram a ser o elemento dominante nessa relação. Um segundo eixo de sua pesquisa desenvolveu-se no sentido de analisar as relações que se estabeleceram entre o caso escolhido para estudo - o conglomerado Folhas - e o contexto social, econômico e político em que se deu sua trajetória.

Depois de periodizar a evolução do Grupo Folhas, a partir da fundação do jornal Folha da Noite, em 1921, e de caracterizar a atuação da empresa em cada uma das etapas que identifica, Taschner (1992) situa na década de 60 o período histórico em que efetivamente os modos de produção da indústria cultural passam a ser incorporados definitivamente pelas empresas editoras de jornais no Brasil. O período coincide, portanto, com a instalação da indústria cultural como um todo no país, atingindo os mais diversos segmentos da produção e circulação de bens e produtos de consumo imaterial.

Segundo a socióloga paulista, é com a formação do conglomerado Folhas que tanto as técnicas quanto a lógica da indústria cultural consolidam-se definitivamente no jornalismo brasileiro. A transferência do comando da empresa, então dirigida por José Nabantino Ramos, para Otávio Frias de Oliveira e Carlos Caldeira Filho, em 1962, marca o início da formação do grande complexo empresarial no ramo do jornalismo em São Paulo, com reflexos na imprensa brasileira em geral. É a partir dessa fase, segundo ela, que a empresa passa a ter predomínio sobre o jornal, invertendo a lógica do período anterior, quando os jornais - que preexistiam à indústria cultural - tinham predomínio sobre as empresas que os editavam.

Deve-se observar a diferença entre esses dois períodos históricos de forma a não entrar em conflito com o que vêm afirmando historiadores de respeitabilidade, como Sodré (1983) e Bahia (1990). Ambos afirmam que já nas primeiras décadas do século $X X$ os jornais brasileiros eram produzidos por organizações empresariais e citam como exemplo os casos de O Estado de São Paulo (1875) e do Jornal do Brasil (1891), periódicos fundados no final do século XIX e que chegam ao século seguinte organizados como empresas. Isso significa que, na transição de um século para outro, esses jornais, ao se apresentarem ao público como um negócio, dizem-se livres da subordinação dos partidos políticos, por exemplo. O lançamento do Correio do Povo (1895), em Porto Alegre, também no final do século XIX, é igualmente ilustrativo dessa "independência". Até então, a imprensa era um dos mais importantes instrumentos de agitação e doutrinação política. Sua instrumentalização fazia parte das estratégias dos grupos em disputa pelo poder.

Nessa fase, que iria de 1880 a 1930 (Bahia, 1990:45), começava a se esboçar uma imprensa de massas, mais preocupada com o leitor e menos em expressar interesses individuais ou de grupos. O período é marcado pela reorganização dos jornais e pela modernização tecnológica - as gráficas foram se separando das tipografias e adquirindo contornos mais industriais. É o período também dos pequenos anúncios, que invadem até mesmo a capa dos jornais, e das notícias, que vão ocupando cada vez mais espaço em relação aos artigos de fundo (opinião).

A esse respeito, Taschner (1992) observa, entretanto, que ainda estávamos longe da imprensa moderna:

"O Estado de São Paulo, ao mesmo tempo em que pretendia construir uma organização sólida, nascia vinculado à 
luta política, aproximando-se, nesse sentido, do que se poderia chamar de um jornal de causa; ou seja, nascera para defender uma determinada linha editorial, um determinado tipo de conteúdo. Este era o pressuposto. A organização empresarial era arcabouço material para se realizar o objetivo político. Não era um jornal para dar lucro independentemente do tipo de mensagem que faria. Nesse sentido, nas relações entre o jornal propriamente dito e "sua empresa", o Estado de São Paulo não era um jornal dominado pela sua organização empresarial, embora esta já existisse e ele certamente não fosse um pasquim". (Taschner, 1992:30-31).

A diferença do período estudado por Taschner (1992) - décadas de 60 e 70 - do período dos jornais-empresa de que falam Sodré (1983) e Bahia (1990) é que, a partir da vigência das regras da indústria cultural, nessa relação, a empresa subordina o produto, verifica-se um processo de assujeitamento da mensagem jornalística à lógica empresarial, o que não ocorria no período anterior.

Entre o período dos jornais-empresa (das primeiras décadas do século $X X$ ) e o período da indústria cultural (dos anos 60 em diante), entretanto, pode-se identificar ainda uma fase de transição. Essa fase é caracterizada pelo emprego das técnicas da indústria cultural nos jornais, mas não da sua lógica. A mensagem jornalística era produzida - apresentava as formas (a embalagem) - segundo as técnicas da indústria cultural, mas ainda não estava subordina às determinações da empresa, ou seja, ainda não se encontrava totalmente subordinada.

Essa fase também foi estudada por Taschner em outro trabalho de pesquisa ${ }^{4}$, em que analisa os casos de Última Hora e Notícias Populares, jornais que, em 1965, passariam a fazer parte do conglomerado Folhas.
Ao lançar Última Hora, na década de 50 , com o objetivo de divulgar o projeto nacional-populista de Getúlio Vargas, Samuel Wainer colocou em circulação um dos mais modernos periódicos da época. Suas inovações gráficas e editoriais são tidas por muitos historiadores - assim como a reforma do Jornal do Brasil como um dos marcos que impulsionaram a modernização da imprensa na década de 60. Notícias Populares, por sua vez, contraponto do liberalismo oligárquico, lançado em 1963 por Herbert Levy (presidente da UDN e homem ligado ao capital financeiro, agrícola e comercial), também apresentava uma mensagem jornalística produzida segundo as mesmas técnicas, embora com outra perspectiva política. Notícias Populares era, aliás, como bem observa Taschner (1987), a imitação pelo avesso do Última Hora.

O problema é que, tanto num caso como no outro, na avaliação da autora, a mensagem desses jornais é que estava politicamente subordinada:

“(...) a mensagem de Última Hora foi o pressuposto em torno do qual se organizou a empresa e não um produto a ela subordinado. Era mercadoria por acréscimo, e não por definição. Assim, de nada adiantou toda a 'organização empresarial avançada'. A primazia da mensagem política po-pulista impediu a afirmação da lógica empresarial ao revelar-se incompatível com ela" (Taschner, 1987:154).

Quanto ao Notícias Populares, da mesma forma observa a socióloga:

"Tal como em Última Hora, a mensagem subordinou a empresa em Notícias Populares. Em contrapartida, sua organização empresarial foi bastante improvisada, especialmente se se levar em conta que este jornal nasceu num momento em que 0 
capitalismo brasileiro estava em sua fase monopolista" (Taschner, 1987: 154)

A autora conclui, então, que foi a luta política que trouxe à luz os dois jornais, porque foi em função da luta política que se determinou a mensagem de ambos.

"Foi em função da luta política que Última Hora sofreu boicote econômico. Foi em função da luta política que os Levy, capitalistas bem-sucedidos em áreas diversas, deram a Notícias Populares uma organização empresarial tão tosca e perderam o interesse pelo jornal assim que se consumou o Golpe de Abril, apesar de Notícias Populares estar fazendo grande sucesso em termos de vendas. Enfim, foi a lógica da política que comandou o destino de Última Hora e Notícias Populares. A ela se subordinaram as demais características. (...) Como empresas, fracassaram." (Taschner, 1987).

Como dissemos anteriormente, tanto Última Hora quanto Notícias Populares foram adquiridos por Otávio Frias de Oliveira e Carlos Caldeira Filho em 1965 e passaram a integrar o conglomerado Folhas. Suas mensagens, assim como as do jornal mais importante do grupo - Folha de São Paulo - , passaram, a partir daí, a ser subordinadas à empresa, a ser integralmente mercadoria. "Teriam agora não só as técnicas, mas também a lógica da indústria cultural." (Taschner, 1987:154)

As características de uma imprensa de indústria cultural

Da leitura dos dois trabalhos de pesquisa da socióloga Gisela Taschner já referidos, pode-se apreender alguns dos elementos constitutivos de uma imprensa de indústria cultural. A primeira dessas características seria, conforme a autora, o caráter de mercadoria da informação.

Essa natureza de produto conferida às notícias possibilitaria inclusive uma maior flexibilidade de linha editorial, ou mesmo de ausência de uma linha editorial, permitindo que o jornal assuma determinadas posições que possam ser corrigidas logo adiante, dependendo dos rumos do vento, da opinião pública. É uma postura diferente da adotada pelos jornais-causa. A Folha da Noite, embrião do Grupo Folhas, teria nascido com esse senso de oportunidade, como uma "mercadoria envergonhada, porque a mensagem-mercadoria serve à lógica e aos espaços do mercado e não necessariamente às opiniões do dono do jornal" (Taschner, 1992: 42).

A propósito do caráter de mercadoria das informações de atualidade produzidas pela imprensa de indústria cultural, cabe aqui resgatar o conceito de notícia formulado por um dos mais importantes autores brasileiros na área da teoria do jornalismo, Ciro Marcondes Filho:

"Notícia é a informação transformada em mercadoria com todos os seus apelos estéticos, emocionais e sensacionais; para isso, a informação sofre um tratamento que a adapta às normas mercadológicas de generalização, padronização, simplificação e negação do subjetivismo. Além do mais, ela é um meio de manipulação ideológica de grupos de poder social e uma forma de poder político". (Marcondes Filho, 1989:13).

O autor em referência antecipa, assim, uma outra característica da imprensa de indústria cultural levantada por Taschner e que diz respeito justamente à embalagem do produto jornal: a "feição leve e graciosa". Segundo a socióloga, essa é uma característica que vai ganhar cada vez maior proeminência à medida que vão evoluindo as técnicas da indústria cultural na imprensa. "É a embalagem do produto 
que começa a ser trabalhada. É também a preocupação em fazer um produto mais digestivo, menos highbrow, mais acessível e sedutor" (Taschner, 1992:42), com o objetivo de fisgar o leitor, o maior número de leitores.

A preocupação com os leitores, aliás, é uma terceira característica. Os jornais precisam interessar a diferentes tipos de leitores. Para isso, são criadas as mais diversas editorias e seções e os mais diversos cadernos e suplementos, de forma a não deixar de agradar a nenhum dos segmentos constitutivos do mercado consumidor: mulheres, empresários, jovens, vestibulandos, desportistas, crianças, etc. Quanto maior for a quantidade de leitores de um jornal, melhores são as condições de esse periódico "se vender" para o mercado publicitário, também interessado nesse público amplo e diversificado. Da mesma forma, como ilustrativo da sujeição da mensagem à lógica empresarial, outros jornais, outros títulos, são lançados como produtos periodicamente no mercado com o objetivo de absorver a demanda de determinado segmento social. No caso do grupo Folhas, a aquisição dos títulos Última Hora e Notícias Populares, em 1965, é típica dessa situação. No Rio Grande do Sul, o lançamento de um jornal popular como o Diário Gaúcho, pelo grupo RBS, também. São exemplos de jornais que constituem produtos de uma mesma empresa e que visam a atingir públicos distintos, com linguagens também distintas. É a embalagem de que fala Marcondes Filho.

Essa busca constante do leitor é criticada também por Lins da Silva ao questionar o modelo americano de jornalismo que historicamente vem influenciando a imprensa brasileira, particularmente a partir dos anos 60 . "Desde pelo menos o final da Segunda Guerra Mundial, o noticiário se entregou cada vez mais à idéia de que a conquista do mercado pela adulação ao consumidor é a única regra do jornalismo." (Lins da Silva,
1991:24). Para o autor, a conseqüência disso é a banalização das notícias.

A importação de modelos, dos Estados Unidos mais especificamente, é justamente a quarta característica, apontada por Taschner (1992), de uma imprensa de indústria cultural no Brasil. Segundo a autora, a importação do modelo americano, a partir dos anos 60, fez com que muitos periódicos tivessem feições típicas da indústria cultural antes mesmo que o país tivesse infra-estrutura material para sua instalação.

A socióloga observa que esses fatos, aliados a fatores externos (como a elevação do índice de pessoas alfabetizadas e a inexistência de concorrentes com capacidade de atualização dos fatos no decorrer do dia), fizeram de empreendimentos como o Grupo Folhas um sucesso absoluto.

\section{Formas de subordinação das mensagens}

Quanto ao assujeitamento da mensagem jornalística pela empresa, o estudo de caso realizado por Gisela Taschner no Grupo Folhas permite-nos observar que esse processo se dá de diversas formas na imprensa de indústria cultural.

Uma dessas formas é a centralização das operações de redação. A criação de agências, por exemplo, cuja finalidade é a produção de notícias e a sua distribuição para todos os veículos ligados ao grupo empresarial (jornais, rádios, tvs, sites, etc.), é uma estratégia empresarial de racionalização do trabalho e de redução de custos. Centralizar a produção das notícias reduz os custos com pessoal, com espaço físico, com meios de transporte e com outros materiais necessários à realização do trabalho. Além disso, permite um maior controle da mensagem que está sendo produzida. Taschner (1992) relata que, à época da censura imposta pelo regime militar, a agência de notícias do Grupo Folhas foi utilizada para centralizar a 
autocensura em todos os jornais do grupo.

Uma conseqüência observável dessa centralização da produção das mensagens é a padronização dos textos, ou a indiferenciação dos produtos de um mesmo grupo editorial, o que gera uma espécie de efeito de consonância. Todos os jornais, ou todos os veículos de comunicação de uma mesma empresa, ficam muito parecidos uns com os outros, tratam mais ou menos dos mesmos assuntos e pela mesma ótica. Os jornais acabam enfrentando precariamente esse tipo de problema - típico da indústria cultural - com a própria fórmula de oferecer fatos novos todos os dias, mas não conseguem superar integralmente as dificuldades para a realização de um trabalho que, mesmo estandardizado, precisa oferecer novidades.

A centralização da produção das notícias em agência tem uma outra conseqüência, que é a possibilidade de a empresa vincular, do ponto de vista trabalhista, todos os jornalistas a essa organização. Assim, todos trabalham para todos os veículos de comunicação da empresa. A estratégia, evidentemente, é muito eficiente para fazer frente às necessidades de redução de custos e de meios, uma contingência empresarial.

Dessa forma, a estrutura de produção dos jornais torna-se cada vez mais complexa, mais burocratizada e mais suscetível aos sistemas de controle. Para dar conta da necessidade de diferenciação dos produtos, Taschner observa, por exemplo, que as editorias transformam-se em verdadeiras minirredações: cada uma tem seu editor, seus repórteres e muitas vezes o seu próprio pauteiro. "Num jornal como a Folha da Tarde, - exemplifica -, a redação é alimentada duplamente: fica em contato com a Agência ao longo do dia, para saber o que os repórteres de lá estão fazendo e que resultados estão obtendo. Ao mesmo tempo, faz a pauta específica e controla o trabalho de seus próprios repórteres."(Taschner, 1992:166).

A autora observa ainda a existência de outros aspectos ligados ao modo de produzir a mensagem jornalística que caracterizam essa sua subordinação à lógica empresarial numa imprensa de indústria cultural. O aumento e a sofisticação do controle sobre o processo de trabalho pode ser percebido, por exemplo, no papel desempenhado pelos manuais de redação, que são cada vez mais detalhados. A importância do manual na execução do trabalho dos jornalistas é tal que ela acaba por desempenhar função semelhante à exercida pelo velho jornalista experiente do passado diante do jovem profissional em início de carreira, quando o ofício era aprendido "no calor das redações".

Os instrumentos de avaliação do profissional jornalista também são poderosas formas de controle. A evolução dos métodos de gerenciamento das redações, sempre com a finalidade de conseguir o máximo de qualidade e produtividade com o mínimo de custos, tem provocado mudanças significativas na forma de avaliar e de remunerar o trabalho dos jornalistas.

Ao analisar as novas relações de trabalho que se estabelecem num mundo profissional marcado pela forte presença das novas tecnologias e os processos de trabalho dentro do setor dinâmico em que se converteram as indústrias culturais, Capparelli (1997) relata a forma de pagamento adotada pelo grupo Rede Brasil Sul de Comunicações (RBS), proprietário do jornal Zero Hora, aos seus profissionais. Segundo o autor, desde 1993 a empresa adota um sistema de remuneração - Plano de Participação nos Resultados (PPR) - que significa uma grande mudança nas relações entre o capital e o trabalho. Por esse sistema, os jornalistas recebem um salário mensal, estabelecido por faixas de tempo de ingresso na empresa e por capacidade. Além dessa forma de pagamento, válida para todos os trabalhadores culturais, a partir de 1996 a empresa também passou a pagar um 
bônus anual para cada funcionário que cumprir metas estabelecidas tanto em equipe quanto individuais.

Quanto às metas por equipe,

“(...)a cada ano as editorias reúnem sua equipe e estabelecem certos objetivos gerais, complementados por objetivos individuais. Se esses objetivos são atingidos, o funcionário pode receber no fim do ano de um a dois salários extras. Diferentemente de uma produção de escala, como acontecia antes, procurou-se chegar a uma produção de qualidade. (...) A redação, por exemplo, pode estabelecer como meta em determinado período um crescimento em credibilidade junto ao público enquanto que o setor industrial pode visar a uma diminuição de perda de papel na fase de impressão". (Capparelli, 1997:122).

Quanto às metas a serem cumpridas individualmente,

“... um repórter sedentário, avesso a deslocamentos muito longos, pode apresentar como meta - ou o chefe de reportagem pode lhe propor - a produção de cinco reportagens especiais, viajando por todo 0 Brasil. A outro repórter pode propor a pontualidade, seja em relação ao início de seu trabalho, seja em relação a atrasos eventuais no baixamento de matérias". (Capparelli, 1997:122).

Como se pode depreender dos exemplos relatados, com esse tipo de controle sobre o trabalho, as notícias ficam cada vez menos diferentes das mercadorias em geral e os jornalistas cada vez mais são tratados como operários de uma fábrica qualquer do ramo tradicional da economia, onde se produzem produtos para consumo material, quando, na verdade, o jornalismo é um produto cultural, de consumo simbólico, imaterial.

Sobre esse aspecto, Taschner (1992) sustenta que o controle se dá simultaneamente sobre o processo de produção da mensagem em conjunto e sobre o desempenho de cada jornalista que dele participa. Sobre este, existem mecanismos de advertência e de congratulações, existem planos de metas a serem atingidas e todo um conjunto de procedimentos que, ao mesmo tempo, controlam e promovem a adaptação do trabalhador ao processo de trabalho.

Uma outra forma caracterizadora da subordinação da mensagem jornalística pela empresa, de acordo com a socióloga paulista, pode ser identificada na política, cada vez mais incentivada, de integração entre os setores administrativo, editorial e industrial (gráfica) dos jornais. A autora relata que na Folha de São Paulo, a partir dos anos 70, foram regulares as reuniões entre esses setores da empresa. Nessas reuniões, segundo the foi relatado em entrevistas, eram comuns as orientações a jornalistas e editores para que produzissem alguma matéria dirigida a algum mercado em que a venda avulsa, por exemplo, estivesse necessitando ser incrementada.

Além disso, as mudanças tecnológicas e de organização industrial das empresas, relativas à reprodução dos exemplares e à sua distribuição, também passaram a afetar o sistema de trabalho nas redações e constituem exemplo do assujeitamento das mensagens à lógica empresarial. Para atender às necessidades de racionalização desses setores da organização, o horário de fechamento das edições, por exemplo, antes ditado pelas necessidades de cobertura dos fatos pelos jornalistas, passa a ser determinado pelo setor industrial e não mais pela redação. Esta, quando muito, negocia o horário de fechamento de uma ou outra página, dependendo da importância do assunto a ser atualizado (o resultado de uma partida de futebol, de uma votação importante no Congresso, etc.), mas, no geral, precisa se submeter às 
determinações dos setores industrial e de circulação.

Um último aspecto a ser destacado no presente trabalho, também revelador da subordinação do jornalismo à lógica da indústria cultural, igualmente identificado por Gisela Taschner no seu estudo sobre a formação do conglomerado Folhas, diz respeito à relação entre matéria editorial, publicidade e quota-papel.

A quota-papel é a quantidade de papel de imprensa que a direção de redação pode dispor por um determinado período de tempo (mensalmente, por exemplo) para a produção do jornal. Essa quantidade é definida pela empresa de acordo com os seus critérios de racionalidade. A partir dessa quantidade, o diretor de redação planeja o número de páginas de cada edição. $O$ setor de publicidade, entretanto, é que define o espaço inicial, programando, página por página, os anúncios a serem inseridos. O que sobra de espaço é que é distribuído entre as várias editorias. Essa divisão é feita em proporções variáveis em função da importância de cada matéria.

Veja-se o exemplo de negociação que se dá no jornal Folha de São Paulo quando um editor-chefe excede sua quota de papel por haver necessitado de mais espaço para a publicação de acontecimentos considerados importantes:

“...ele não poderá deslocar os anúncios. Pode tentar aumentar o número de páginas daquela edição (...), mas sua margem de manobra é relativamente estreita. Se o editorchefe exceder a sua quota, há um complicado mecanismo através do qual terá de se justificar para eventualmente conseguir mais papel. Isto pressiona a redação a manter suas matérias de modo a apenas preencher os espaços deixados em branco pelos anúncios."(Taschner, 1992:175).

Acrescentaríamos ainda, para finalizar, uma outra forma de subordinação da mensagem jornalística à lógica empresarial de procurar seduzir o maior número possível de leitores. Essa forma está diretamente vinculada à produção do texto e aos modelos de objetividade importados. Trata-se das constantes reformulações gráficas das páginas e de estruturação dos textos das notícias com o objetivo de facilitar a leitura. A chamada linguagem média, a linguagem jornalística, tem sido levada ao extremo da simplificação, a ponto de retirar das notícias - cada vez mais breves, mais curtas - qualquer possibilidade de contextualização. Isso tem contribuído para o empobrecimento da interpretação dos fatos. Títulos, boxes, infográficos, fotografias, legendas, resumos, artes, etc. - enfim, todos os recursos vêm sendo utilizados para melhorar e tornar mais atraente a embalagem da informação.

Para agradar ao leitor sem tempo para a leitura, ou não habituado a ela, os jornais parecem-se cada vez mais com o rádio e a televisão, renunciando, assim, à sua função de aprofundar o conhecimento e a análise dos eventos que noticia.

Todos esses fatores, para os objetivos do presente trabalho, parecemnos suficientes para comprovar a sujeição dos conteúdos jornalísticos à lógica de produção da indústria cultural.

O jornal da indústria cultural não é mais um jornal cuja organização tem a forma de empresa, como nos primórdios do século XX. "Trata-se de uma empresa que tem atividade jornalística. Ela é o sujeito, e não mais o jornal. Este é o produto da atividade da empresa", ajuda-nos a concluir Taschner (1992:67).

\section{Conclusão}

Não estavam entre os objetivos do presente trabalho analisar as conseqüências, ou as implicações, desse "modo de produção" da indústria jornalística sobre a sociedade. Este seria um desafio que renderia, por si só, uma reflexão à parte, que nos remeteria 
inclusive para outras abordagens teóricometodológicas, mais voltadas para o estudo da ética e mesmo dos efeitos dos meios de comunicação no processo de construção da realidade.

Por outro lado, constatar a subordinação do jornalismo às técnicas e à lógica da indústria cultural não significa admitir que em períodos anteriores a esse a atividade tenha se desempenhado de forma independente. Vários estudos, realizados tanto pela História quanto pela Sociologia ou pela Ciência Política, têm demonstrado o assujeitamento da imprensa a outras lógicas, outros valores, em distintos períodos históricos. No início do século XIX, por exemplo, os pasquins foram a expressão e a linguagem da imprensa instrumentalizada pelos distintos grupos políticos em conflito de interesse no momento seguinte à Independência, quando havia uma estrutura de Estado a ser delineada. No final do mesmo século, especialmente no seu último quartel, a imprensa continuava a ser o poderoso instrumento de mobilização social pelas reformas que a nação passava a exigir. Basta, para isso, ver o papel desempenhado pelos jornais nas campanhas abolicionista e republicana. E no século $X X$, como já referimos, numa fase em que já se empregavam as técnicas da indústria cultural, os jornais continuavam a obedecer às determinações dos grupos políticos que Ihes financiavam - vejamse os casos de Última Hora e Notícias Populares.

Dessa forma, podemos dizer que o modelo ideal de jornalismo, praticado sem quaisquer restrições, quaisquer constrangimentos, sejam de natureza política ou econômica, continua sendo uma meta, uma utopia não apenas de jornalistas mas de toda a sociedade. Acredita-se que a possibilidade de o jornalismo ser a expressão da verdade é falsa, porque a objetividade é impossível. Mas compartilhamos com Marcondes Filho (1989) a idéia de que há apropriações mais ou menos próximas da verdade dos fatos, que evitam e denunciam os sofismas que funcionam como instrumentos ocultos de persuasão. A crescente mercantilização das notícias e dos jornais, a sua subordinação às estratégias de marketing na obstinada captura de leitores-consumidores, está levando os periódicos impressos a um processo de simplificação extremo, que acaba por lhes subtrair o papel de esclarecimento, aprofundamento e análise das notícias que deles se espera.

Também não tratamos no presente trabalho, deixando como questão de pesquisa para ser retomada em outra oportunidade, das implicações da indústria cultural no segmento da imprensa sobre o perfil dos jornalistas. Quem eram os profissionais e como interpretavam seu papel na sociedade antes do advento da indústria cultural na sua profissão? A introdução da lógica da indústria cultural no seu campo de trabalho provocou algum tipo de alteração nesse perfil? Quais? Como se vêem e como percebem o seu papel na sociedade nesta fase de extrema profissionalização em que se inserem as empresas para as quais trabalham, num cenário de convergência tecnológica e financeira?

Da mesma forma, deixamos de considerar as implicações do novo fenômeno deste período de transição entre os séculos $X X$ e $X X I$ - o fenômeno da sociedade em rede (conceito de Manuel Castells, autor da já clássica trilogia "A Era da Informação") -, que produz impactos de outras naturezas nas estruturas de produção de notícias e outras formas de subordinação destas à lógica da agora nova forma de organização social.

Essas e outras são questões que se colocam imperativas ao final das reflexões que até aqui empreendemos. Pela pertinência e pela complexidade que encerram, ficam para ser retomadas oportunamente. 


\section{Notas}

1 Professora da FABICO/UFRGS; doutoranda no Programa de Pós-Graduação em Comunicação e Informação (PPGCOM) da Universidade Federal do Rio Grande do Sul.

2 Conforme Sérgio Capparelli, em curso no PPGCOM da UFRGS em 2001.

3 TASCHNER, Gisela. Folhas ao vento: análise de um conglomerado jornalístico no Brasil. Rio de Janeiro: Paz e Terra, 1992.

4 GOLDENSTEIN, Gisela Taschner. Do jornalismo político à indústria cultural. São Paulo: Summus, 1987.

\section{Referências}

BAHIA, Juarez. Jornal, história e técnica. São Paulo: Ática, 1990.

CAPPARELLI, Sérgio. "Zanzibar de novas tecnologias: imprensa regional e Zero Hora". In: Temas contemporâneos em comunicação. São Paulo: Edicon/Intercom, 1997 (109126).

CASTELLS, Manuel. A sociedade em rede. São Paulo: Paz e Terra, 1999.

.O poder da identidade. São Paulo: Paz e Terra, 1999.

HORKHEIMER, Max e ADORNO, Theodor W. "A indústria cultural: 0 iluminismo como mistificação de massas". In: LIMA, Luiz Costa. Teoria da Cultura de Massa. $3^{a}$ edição. Rio de Janeiro: Paz e Terra, 1982 (159-204).

LINS DA SILVA, Carlos Eduardo. 0 adiantado da hora: a influência americana sobre 0 jornalismo brasileiro. São Paulo: Summus, 1991

LOPES, Maria Immacolata Vassalo. Pesquisa em comunicação: formulação de um modelo metodológico. São Paulo: Loyola, 1994.

MARCONDES FILHO, Ciro. 0 capital da notícia: jornalismo como produção social de segunda natureza. São Paulo: Ática, 1989.
MATTELART, Armand e Michèle. História das teorias da comunicação. $2^{a}$ edição. São Paulo: Loyola, 1999.

ORTIZ, Renato. A moderna tradição brasileira: cultura brasileira e indústria cultural. $3^{a}$ edição. São Paulo: Brasiliense,1991.

TASCHNER, Gisela. Folhas ao vento: análise de um conglomerado jornalístico no Brasil. Rio de Janeiro: Paz e Terra, 1992

Do jornalismo político à indústria cultural. São Paulo: Summus, 1987.

RÜDIGER, Francisco. Tendências do jornalismo. Porto Alegre: Ed. da Universidade/UFRGS, 1993.

SODRÉ, Nelson Werneck. A história da imprensa no Brasil. São Paulo: Martins Fontes, 1983. 